\title{
Recovery of Anastomosis Groups of Rhizoctonia solani from Different Latitudinal Positions and Influence of Temperatures on Their Growth and Survival
}

\author{
R. Harikrishnan and X. B. Yang, Department of Plant Pathology, Iowa State University, Ames 50011
}

\begin{abstract}
Harikrishnan, R., and Yang, X. B. 2004. Recovery of anastomosis groups of Rhizoctonia solani from different latitudinal positions and influence of temperatures on their growth and survival. Plant Dis. 88:817-823.

Multinucleate Rhizoctonia solani isolates were recovered from soybean fields from five locations at a range of latitudes from 33 to $46^{\circ} \mathrm{N}$. Out of 143 multinucleate isolates recovered, 51 isolates were anastomosis group (AG)-1 (35.6\%), 9 were AG-2-2 (6.2\%), 40 were AG-4 (28\%), and 15 were AG-5 (10.6\%). The remaining 28 isolates (19.6\%) failed to anastomose with any of the testers (AG-1, 2-2, 4, or 5). Among the four AGs, AG-1 was found mainly in the more southern latitudes in contrast to AG-2-2, which was found mostly in the more northern latitudes. AG-4 and AG-5 were distributed across all latitudes. Effects of temperature on growth, sclerotia production (range from 5 to $30^{\circ} \mathrm{C}$ with $5^{\circ}$ increments), and saprophytic survival using infested straw (range from -10 to $30^{\circ} \mathrm{C}$ with $10^{\circ}$ increments) were studied with representative isolates from AG-1, AG-2-2, AG-4, and AG-5 isolated from different locations. Results indicate differential effects of temperature on growth rate and sclerotia production among the isolates within each AG. Optimum temperature for growth rate of all isolates tested from the different AGs was between 25 and $30^{\circ} \mathrm{C}$; whereas, for sclerotia production, it was $25^{\circ} \mathrm{C}$. Isolates from AG-1 had the highest mean sclerotia production. Saprophytic survival of isolates from all AGs tested declined linearly over time and with decrease in temperature in the survival study. Saprophytic survival of all isolates irrespective of AG collected from the southernmost location was lower at low temperatures than that of isolates collected from higher latitudes. Our results suggest temperaturedependent response among isolates within different AGs of $R$. solani.
\end{abstract}

Additional keyword: distribution

Rhizoctonia solani Kühn (teleomorph = Thanatephorus cucumeris (A.B. Frank) Donk) is a major pathogen on soybean (Glycine max L.), causing diseases such as damping-off, root and stem rots, and foliar blight in most soybean-growing regions of the world (13). Severe yield losses due to this pathogen have been reported (16). Isolates of $R$. solani are classified into 14 anastomosis groups (AGs), AG-1 to AG-13 and AG-BI, based on hyphal anastomosis, cultural morphology, pathogenicity, and DNA homology (4). AG-1 is further subdivided into AG-1 1A, 1B, 1C, and AG-2 into AG-2-1 and AG-2-2. On soybean, AG-1 $1 \mathrm{~A}$ and AG-1 1B cause aerial blight and web blight, respectively; while the other AGs gener-

Corresponding author: X. B. Yang

E-mail: xbyang@iastate.edu

Current address of R. Harikrishnan: Department of Plant Pathology, North Dakota State University, P.O. Box 5012, Fargo 58105-5012.

This work is part of a dissertation by R. Harikrishnan for the Graduate College, Iowa State University.

Accepted for publication 22 March 2004.

Publication no. D-2004-0601-01R

(C) 2004 The American Phytopathological Society ally are responsible for seed, root, and stem rots.

There are several cultural and environmental factors that influence the distribution and survival of soil microorganisms. Of the various environmental factors, temperature has been postulated as a major criterion affecting the distribution, growth, and survival of microorganisms and fungi (11). There are several studies that report variability on a regional level among various AGs of $R$. solani recovered from soybean. Nelson et al. (9) found that, of the 102 isolates of $R$. solani recovered from soybean in North Dakota, AG-4 and AG-5 constituted 46 and $38 \%$, respectively. Another study found that isolates of $R$. solani recovered from soybean in Zaire (Africa) and Ohio belonged to different AGs (8). In Minnesota, Windels and Nabben (18) recovered 325 multinucleate isolates of $R$. solani from sugar beet which predominantly belonged to AG-4, AG-5, and AG-22. Rush et al. (12) from Texas found that $89 \%$ of the isolates recovered from sugar beet belonged to AG-2-2. However, there is a lack of understanding of the distribution of different AGs in R. solani across a wide geographic area and the likely reason for such variation. Thus, the objectives of this study were to characterize $R$. solani from soybean fields from a range of latitudes and to determine the effect of tem- perature on growth and survival of different AGs of $R$. solani isolated from these locations. A preliminary report of this study has been published (5).

\section{MATERIALS AND METHODS}

Study area and soil sampling. Soil samples were collected during the growing season in July and August 1998. Soil samples were collected at sites located at five different latitudes: $46.5^{\circ} \mathrm{N}$ (Detroit Lakes, $\mathrm{MN}), 43.2^{\circ} \mathrm{N}$ (Forrest City, IA), $40.1^{\circ} \mathrm{N}$ (Holt, MO), $35.6^{\circ} \mathrm{N}$ (Blytheville, $\mathrm{AK}$ ), and $33.4^{\circ} \mathrm{N}$ (Cleveland, MS). Within each location, five soybean fields were arbitrarily chosen in an 8-km radius. In each field, soil samples were collected from five representative areas to depth of 5 to $10 \mathrm{~cm}$ in a zigzag manner. A total of approximately $1 \mathrm{~kg}$ of soil was collected from each field. Soil samples were mixed thoroughly for each field and brought back in cooler boxes and stored at $4^{\circ} \mathrm{C}$ for further processing.

Isolation. Soil (100 g) from each field was passed through a mesh $(250 \mu \mathrm{m}$ in diameter) by running tap water to collect residues. The residue collected was air dried overnight at $25 \pm 2{ }^{\circ} \mathrm{C}$ and was used for isolation of $R$. solani. Initial isolations were made by placing $2 \mathrm{~g}$ of residue in petri dishes filled with water agar containing streptomycin sulfate at $100 \mathrm{mg} / \mathrm{liter}$. After 24 to $48 \mathrm{~h}$ of incubation in the dark at $25 \pm 2{ }^{\circ} \mathrm{C}$, hyphae resembling $R$. solani were transferred to potato dextrose agar containing streptomycin sulfate at 100 $\mathrm{mg} /$ liter (PDAS) for further purification and identification.

Identification, characterization, and anastomosis grouping. Identification of $R$. solani was based on hyphal characteristics (14). Mycelia from cultures on PDAS and incubated at $25 \pm 2{ }^{\circ} \mathrm{C}$ in the dark for 2 to 4 days were stained with $0.5 \%$ safranin $\mathrm{O}$ and $3 \% \mathrm{KOH}(1)$ and cells were examined microscopically at $\times 400$ magnification for nuclei estimation.

Cultures of $R$. solani were paired with tester isolates of known AG-1, AG-2-2, AG-4, and AG-5 as described by Kronland and Stanghellini (7). These four AGs were tested because they are commonly reported in association with soybean (9). Testers were provided by D. E. Mathre, Montana State University (AG-1), C. E. Windels, University of Minnesota (AG-2-2), and C. A. Martinson, Iowa State University (AG-4 and AG-5). Two pairings were made of each unknown isolate with the respective 
testers. In each pairing test, 10 contact points were observed at $\times 400$ magnification and were scored as described by Carling (3).

Effect of temperature on in-vitro growth and sclerotia production. Five representative isolates (one isolate from each location if present) chosen arbitrarily from each group (AG-1, 2-2, 4, and 5) were used for this study. Petri dishes filled with PDAS were inoculated with a $3-\mathrm{mm}$ agar disk of the representative isolates from a 2- to 3-day-old culture grown in the dark at $25 \pm 2{ }^{\circ} \mathrm{C}$. The petri dishes were incubated in the dark in incubators set at temperatures of $5,10,15,20,25$, and $30 \pm$ $2{ }^{\circ} \mathrm{C}$. Radial growth measurements were taken daily up to 7 days or until growth reached the edge of the plate, whichever was earlier, on each of the isolates belonging to the various AGs, and mean growth rate per day was calculated. The petri dishes were incubated further for a period of 3 months for sclerotial production. Scle-

Table 1. Relative recovery of isolates belonging to different anastomosis groups (AGs) of Rhizoctonia solani across various latitudinal locations $\left({ }^{\circ} \mathrm{N}\right)^{\mathrm{z}}$

\begin{tabular}{lccccc}
\hline & \multicolumn{5}{c}{ Latitude $\left({ }^{\circ} \mathbf{N}\right)$} \\
\cline { 2 - 6 } AG & $\mathbf{4 6 . 5}$ & $\mathbf{4 3 . 2}$ & $\mathbf{4 0 . 1}$ & $\mathbf{3 5 . 6}$ & $\mathbf{3 3 . 4}$ \\
\hline 1 & 0 & 0 & 5 & 10 & 36 \\
$2-2$ & 6 & 2 & 1 & 0 & 0 \\
4 & 7 & 8 & 6 & 5 & 14 \\
5 & 3 & 1 & 7 & 1 & 3 \\
Unknown & 3 & 4 & 6 & 4 & 11 \\
Total & 19 & 15 & 25 & 20 & 64 \\
\hline
\end{tabular}

${ }^{\mathrm{z}}$ Mean of five fields/location and one location/latitude. rotia production was scored on these petri dishes based on a 0 -to- 5 scale, where $0=$ no sclerotia, $1=1$ to 5 sclerotia, $2=6$ to 10 sclerotia, $3=11$ to 15 sclerotia, $4=16$ to 20 sclerotia, $5=>20$ sclerotia. Each isolate per AG was replicated four times per temperature, and the experiment was repeated.

Survival study at different temperatures. This study was conducted to evaluate the saprophytic (mycelial) survival ability of different AGs under differing temperatures. Two isolates (one each from extreme latitudinal locations if present) belonging to groups AG-1, 2-2, 4, and 5 were employed in this study. The rationale behind using isolates from extreme latitudinal locations was that the isolates are less likely to be adapted to the extreme temperature variation during the year. Isolates were cultured on autoclaved powdered soybean straw (residue size $\leq 250 \mu \mathrm{m}$ ) and incubated in the dark at $25 \pm 2{ }^{\circ} \mathrm{C}$ for 14 days. The powdered straw was autoclaved twice over a two-day period at $121^{\circ} \mathrm{C}$ and $15 \mathrm{lb}$ of pressure for $30 \mathrm{~min}$. Initial popu-
Growth: $\mathrm{Y}=-0.16+0.06(\mathrm{x}) \mathrm{R}^{2}=0.98$

Sclerotia: $\mathrm{Y}=-2.61+3.27(\mathrm{x})+(-) 0.39\left(\mathrm{x}^{2}\right)$ $\mathrm{R}^{2}=0.93$
Growth: $\mathrm{Y}=0.10+0.37(\mathrm{x}) \mathrm{R}^{2}=0.82$

Sclerotia: $\mathrm{Y}=-2.15+1.91(\mathrm{x})+(-) 0.18\left(\mathrm{x}^{2}\right)$ $\mathrm{R}^{2}=0.86$

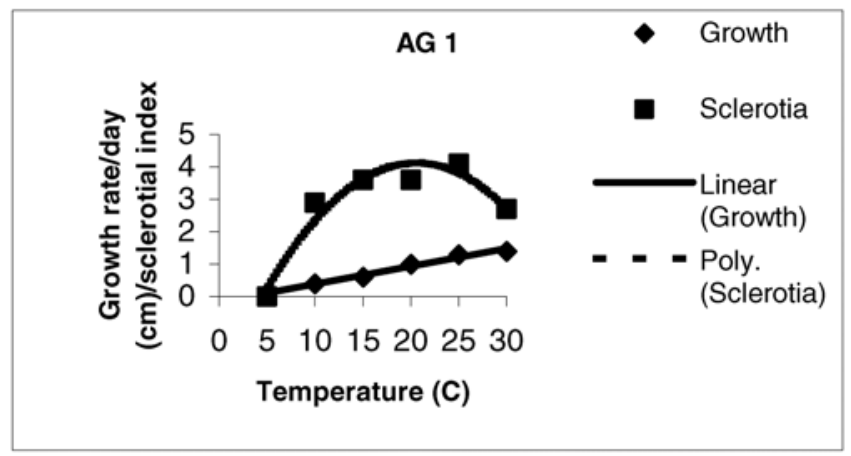

Growth: $\mathrm{Y}=-0.53+0.044(\mathrm{x}) \mathrm{R}^{2}=0.93$

Sclerotia: $\mathrm{Y}=-2.13+2.55(\mathrm{x})+(-) 0.32\left(\mathrm{x}^{2}\right)$ $\mathrm{R}^{2}=0.86$

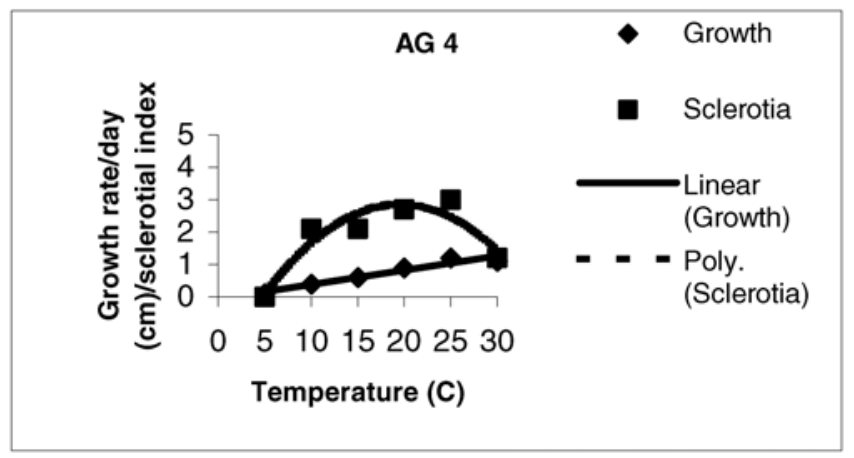

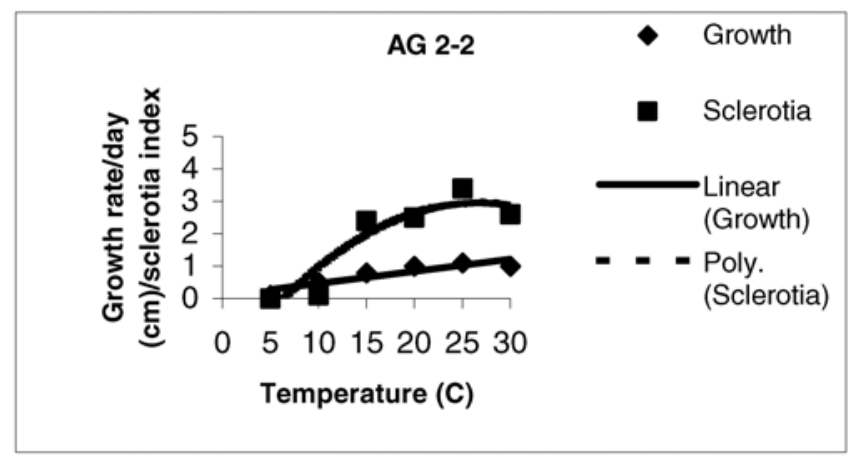

Growth: $\mathrm{Y}=-0.08+0.05(\mathrm{x}) \mathrm{R}^{2}=0.95$

Sclerotia: $Y=-1.76+1.85(x)+(-) 0.17\left(x^{2}\right)$

$\mathrm{R}^{2}=0.83$

Fig. 1. Regression analysis of mean radial growth and sclerotial production of five representative isolates of Rhizoctonia solani belonging to anastomosis group (AG)-1, AG-2-2, AG-4, and AG-5 on potato dextrose agar with streptomycin sulfate at $100 \mathrm{mg} / \mathrm{liter}$ at 5 to $30^{\circ} \mathrm{C}$. Each datum point is a mean of four replications and two experiments. 
lation, in colony forming units per gram of straw, was estimated using serial dilution technique. Four samples of $1 \mathrm{~g}$ each of the air-dried (overnight) infested straw were taken and serially diluted to $1 \times 10^{-4}$. A $0.1-\mathrm{ml}$ aliquot of each dilution was plated onto PDAS with three samples per dilution. The plates were incubated in the dark at $25 \pm 2{ }^{\circ} \mathrm{C}$ for 2 to 3 days. CFU of $R$. solani were identified, counted, and expressed as CFU/g of straw.

Infested straw $(5 \mathrm{~g})$ of each isolate was placed approximately at the center of a Styrofoam cup (size, 6 by $9 \mathrm{~cm}$ ) filled with autoclaved sandy loam soil. The soil was autoclaved as previously described. The cups (24 cups/isolate) were incubated at $-10,0,10,20$, and $30 \pm 2^{\circ} \mathrm{C}$ in the dark for a period of 12 weeks. Initially, the moisture was brought up to field capacity and was readjusted twice per week for cups in temperatures $>20^{\circ} \mathrm{C}$ and once per week for cups in temperatures $\leq 20^{\circ} \mathrm{C}$. At the end of 4,8 , and 12 weeks, two cups from each isolate (within each $\mathrm{AG}$ ) per temperature were taken for population estimation. The straw from the cups was retrieved by washing in running tap water. The straw was air dried overnight, and the population was estimated by serial-dilution plating as described earlier. The study was conducted twice.

Data analysis. The effects of temperature, AG, and their two-way interactions on growth rate and sclerotia production, and the effects of temperature, AG, time, and their two-way and three-way interactions on saprophytic survival were determined using analysis of variance in the PROC GLM procedure of SAS (SAS Institute, Cary, NC). Effects of temperature on growth rate and sclerotia production among isolates within each AG were compared using Fisher's protected least significant difference test at $P=0.05$. Mean growth rate and sclerotial production among AGs were analyzed using linear and quadratic regressions to understand the trend across different temperatures.

For the saprophytic survival study, population densities were log transformed $(\ln (\mathrm{x}))$ before analysis. Simple linear regression was used to estimate slopes and intercepts. The model was evaluated using coefficient of determination $\left(R^{2}\right)$. Data were combined for repetitions within each study following test for homogeneity.

\section{RESULTS}

Recovery and characterization of $R$. solani. In all, 143 multinucleate isolates of

Table 2. Analysis of variance showing the effects of anastomosis group (AG), temperature, and time on growth rate, sclerotia production (SP), and survival of different isolates of Rhizoctonia solani

\begin{tabular}{|c|c|c|c|c|c|c|c|}
\hline \multirow[b]{2}{*}{ Source of variation ${ }^{x}$} & \multirow[b]{2}{*}{$\mathbf{d f}^{\mathbf{y}}$} & \multicolumn{2}{|c|}{ Growth rate } & \multicolumn{2}{|c|}{ SP } & \multicolumn{2}{|c|}{ Survival } \\
\hline & & $F$ & $P>F$ & $F$ & $P>F$ & $F$ & $P>F$ \\
\hline $\mathrm{AG}(\mathrm{G})$ & $3(3)$ & 17.7 & 0.0001 & 17.5 & 0.0001 & 167.4 & 0.0001 \\
\hline Temperature (T) & $4(5)$ & 661.6 & 0.0001 & 86.3 & 0.0001 & 17.9 & 0.0001 \\
\hline $\mathrm{G} \times \mathrm{T}$ & $12(15)$ & 7.1 & 0.0001 & 5.1 & 0.0001 & 1.5 & 0.13 \\
\hline Time (TI) & 2 & $\mathrm{NA}^{\mathrm{z}}$ & NA & NA & NA & $1,806.9$ & 0.0001 \\
\hline $\mathrm{T} \times \mathrm{TI}$ & 8 & NA & NA & NA & NA & 5.3 & 0.0001 \\
\hline $\mathrm{G} \times \mathrm{TI}$ & 6 & NA & NA & NA & NA & 112.4 & 0.0001 \\
\hline $\mathrm{T} \times \mathrm{G} \times \mathrm{TI}$ & 24 & NA & NA & NA & NA & 1.4 & 0.08 \\
\hline
\end{tabular}

${ }^{x}$ Data are means of two experiments and four AGs with five isolates each for growth rate and sclerotia experiments and with two isolates from each AG in the survival experiments.

y Degrees of freedom for the various variables for the survival experiment; values in the parenthesis are for the growth and sclerotia production studies.

${ }^{\mathrm{z}} \mathrm{NA}=$ not applicable.

Table 3. Growth rate and sclerotial production of isolates of Rhizoctonia solani belonging to anastomosis group (AG)-1, AG-2-2, AG-4, and AG-5 cultured on potato dextrose agar supplemented with streptomycin sulfate at $100 \mathrm{mg} /$ liter at 5 to $30^{\circ} \mathrm{C}$

\begin{tabular}{|c|c|c|c|c|c|c|c|c|c|c|c|c|}
\hline \multirow[b]{3}{*}{ Isolate $^{y}$} & \multicolumn{12}{|c|}{ Temperature $\left({ }^{\circ} \mathbf{C}\right)$} \\
\hline & \multicolumn{2}{|c|}{5} & \multicolumn{2}{|c|}{10} & \multicolumn{2}{|c|}{15} & \multicolumn{2}{|c|}{20} & \multicolumn{2}{|c|}{25} & \multicolumn{2}{|c|}{30} \\
\hline & $\mathbf{G}^{\mathbf{z}}$ & $\mathbf{S}$ & $\mathbf{G}$ & $\mathbf{S}$ & $\mathbf{G}$ & $\mathbf{S}$ & G & $\mathbf{S}$ & G & $\mathbf{S}$ & $\mathbf{G}$ & $\mathbf{S}$ \\
\hline \multicolumn{13}{|l|}{ AG-1 } \\
\hline MO 7-3 & 0 & 0 & $0.4 \mathrm{a}$ & $5.0 \mathrm{a}$ & $0.5 \mathrm{~b}$ & $5.0 \mathrm{a}$ & $1.0 \mathrm{a}$ & $5.0 \mathrm{a}$ & $1.3 \mathrm{a}$ & $5.0 \mathrm{a}$ & $1.3 \mathrm{a}$ & $1.3 \mathrm{c}$ \\
\hline AK 1-1 & 0 & 0 & $0.4 \mathrm{a}$ & $1.0 \mathrm{c}$ & $0.5 \mathrm{~b}$ & $1.8 \mathrm{c}$ & $1.2 \mathrm{a}$ & $2.5 \mathrm{c}$ & $1.4 \mathrm{a}$ & $3.5 \mathrm{~b}$ & $1.4 \mathrm{a}$ & $4.3 \mathrm{a}$ \\
\hline MS 1-1 & 0 & 0 & $0.3 \mathrm{~b}$ & $1.3 \mathrm{c}$ & $0.8 \mathrm{a}$ & $1.8 \mathrm{c}$ & $1.0 \mathrm{a}$ & $1.3 \mathrm{~d}$ & $1.4 \mathrm{a}$ & $2.3 \mathrm{c}$ & $1.3 \mathrm{a}$ & $1.0 \mathrm{c}$ \\
\hline MS 2-1 & 0 & 0 & $0.3 \mathrm{~b}$ & $2.0 \mathrm{~b}$ & $0.4 \mathrm{~b}$ & $5.0 \mathrm{a}$ & $1.0 \mathrm{a}$ & $4.0 \mathrm{~b}$ & $1.3 \mathrm{a}$ & $4.8 \mathrm{a}$ & $1.4 \mathrm{a}$ & $4.0 \mathrm{ab}$ \\
\hline \multirow{2}{*}{\multicolumn{13}{|c|}{ AG-2-2 }} \\
\hline & & & & & & & & & & & & \\
\hline MN 3-3 & $0.2 \mathrm{a}$ & 0 & $0.5 \mathrm{a}$ & $0 \mathrm{~b}$ & $0.9 \mathrm{a}$ & $4.5 \mathrm{a}$ & $1.1 \mathrm{a}$ & $4.5 \mathrm{a}$ & $1.4 \mathrm{a}$ & $5.0 \mathrm{a}$ & $1.0 \mathrm{~b}$ & $3.8 \mathrm{~b}$ \\
\hline MN 3-6 & $0.2 \mathrm{a}$ & 0 & $0.6 \mathrm{a}$ & $0 \mathrm{~b}$ & $0.8 \mathrm{a}$ & $0 \mathrm{c}$ & $1.0 \mathrm{~b}$ & $0 \mathrm{c}$ & $1.0 \mathrm{~b}$ & $0 \mathrm{c}$ & $1.0 \mathrm{~b}$ & $0 \mathrm{~d}$ \\
\hline MN 4-4 & $0.2 \mathrm{a}$ & 0 & $0.6 \mathrm{a}$ & $0 \mathrm{~b}$ & $0 \mathrm{a}$ & $5.0 \mathrm{a}$ & $1.1 \mathrm{a}$ & $4.8 \mathrm{a}$ & $1.4 \mathrm{a}$ & $5.0 \mathrm{a}$ & $1.0 \mathrm{~b}$ & $3.5 \mathrm{~b}$ \\
\hline IA $1-2$ & $0.2 \mathrm{a}$ & 0 & $0.5 \mathrm{a}$ & $0 \mathrm{~b}$ & $0.7 \mathrm{a}$ & $0.5 \mathrm{c}$ & $1.0 \mathrm{ab}$ & $0.3 \mathrm{c}$ & $1.2 \mathrm{a}$ & $1.8 \mathrm{~b}$ & $1.0 \mathrm{~b}$ & $1.3 \mathrm{c}$ \\
\hline MO 7-2 & $0 \mathrm{~b}$ & 0 & $0.4 \mathrm{~b}$ & $1.0 \mathrm{a}$ & $0.8 \mathrm{a}$ & $1.8 \mathrm{~b}$ & $1.0 \mathrm{ab}$ & $3.0 \mathrm{~b}$ & $1.4 \mathrm{a}$ & $5.0 \mathrm{a}$ & $2.1 \mathrm{a}$ & $4.5 \mathrm{a}$ \\
\hline \multicolumn{13}{|l|}{ AG-4 } \\
\hline MN 3-1 & $0.1 \mathrm{a}$ & 0 & $0.4 \mathrm{a}$ & $0 \mathrm{c}$ & $0.5 \mathrm{a}$ & $0 \mathrm{~d}$ & $0.7 \mathrm{~b}$ & $0 \mathrm{c}$ & $1.2 \mathrm{a}$ & $0 \mathrm{c}$ & $0.8 \mathrm{c}$ & $0 \mathrm{c}$ \\
\hline IA $1-1$ & $0.1 \mathrm{a}$ & 0 & $0.3 \mathrm{~b}$ & $0 \mathrm{c}$ & $0.5 \mathrm{a}$ & $0 \mathrm{~d}$ & $0.7 \mathrm{~b}$ & $0 \mathrm{c}$ & $1.1 \mathrm{a}$ & $0 \mathrm{c}$ & $1.0 \mathrm{bc}$ & $0.3 \mathrm{c}$ \\
\hline MO 7-1 & $0 \mathrm{~b}$ & 0 & $0.4 \mathrm{a}$ & $3.3 \mathrm{~b}$ & $0.5 \mathrm{a}$ & $5.0 \mathrm{a}$ & $1.0 \mathrm{a}$ & $4.3 \mathrm{~b}$ & $1.4 \mathrm{a}$ & $4.8 \mathrm{a}$ & $1.3 \mathrm{ab}$ & $4.0 \mathrm{a}$ \\
\hline AK 3-2 & $0 \mathrm{~b}$ & 0 & $0.4 \mathrm{a}$ & $3.5 \mathrm{ab}$ & $0.6 \mathrm{a}$ & $2.3 \mathrm{c}$ & $1.2 \mathrm{a}$ & $4.3 \mathrm{~b}$ & $1.3 \mathrm{a}$ & $4.0 \mathrm{~b}$ & $1.4 \mathrm{a}$ & $0.5 \mathrm{c}$ \\
\hline MS 2-8 & $0 \mathrm{~b}$ & 0 & $0.3 \mathrm{~b}$ & $3.8 \mathrm{a}$ & $0.5 \mathrm{a}$ & $3.0 \mathrm{~b}$ & $1.2 \mathrm{a}$ & $5.0 \mathrm{a}$ & $1.3 \mathrm{a}$ & $5.0 \mathrm{a}$ & $1.3 \mathrm{ab}$ & $1.3 \mathrm{~b}$ \\
\hline \multicolumn{13}{|l|}{ AG-5 } \\
\hline MN 3-2 & $0.2 \mathrm{a}$ & 0 & $0.5 \mathrm{a}$ & $0 \mathrm{~b}$ & $0.9 \mathrm{a}$ & $0 \mathrm{~d}$ & $1.2 \mathrm{a}$ & $1.3 \mathrm{~b}$ & $1.4 \mathrm{a}$ & $5.0 \mathrm{a}$ & $0.7 \mathrm{c}$ & $4.8 \mathrm{a}$ \\
\hline IA $1-6$ & $0.2 \mathrm{a}$ & 0 & $0.5 \mathrm{a}$ & $0 \mathrm{~b}$ & $0.6 \mathrm{~b}$ & $0 \mathrm{~d}$ & $0.5 \mathrm{~b}$ & $0 \mathrm{c}$ & $1.1 \mathrm{~b}$ & $1.3 \mathrm{~b}$ & $1.3 \mathrm{~b}$ & $0.3 \mathrm{~d}$ \\
\hline MO 7-4 & $0 \mathrm{~b}$ & 0 & $0.4 \mathrm{~b}$ & $3.5 \mathrm{a}$ & $0.8 \mathrm{a}$ & $4.3 \mathrm{a}$ & $1.0 \mathrm{a}$ & $5.0 \mathrm{a}$ & $1.4 \mathrm{a}$ & $5.0 \mathrm{a}$ & $2.0 \mathrm{a}$ & $3.5 \mathrm{~b}$ \\
\hline AK 1-5 & $0 \mathrm{~b}$ & 0 & $0.4 \mathrm{~b}$ & $0.5 \mathrm{~b}$ & $0.8 \mathrm{a}$ & $1.3 \mathrm{c}$ & $1.0 \mathrm{a}$ & $1.0 \mathrm{~b}$ & $1.4 \mathrm{a}$ & $5.0 \mathrm{a}$ & $2.0 \mathrm{a}$ & $1.5 \mathrm{c}$ \\
\hline MS $1-10$ & $0 \mathrm{~b}$ & 0 & $0.4 \mathrm{~b}$ & $3.0 \mathrm{a}$ & $0.7 \mathrm{ab}$ & $3.5 \mathrm{~b}$ & $1.0 \mathrm{a}$ & $5.0 \mathrm{a}$ & $1.4 \mathrm{a}$ & $4.8 \mathrm{a}$ & $1.4 \mathrm{~b}$ & $3.0 \mathrm{~b}$ \\
\hline
\end{tabular}

${ }^{y}$ Designations for isolates: $\mathrm{MN}=$ Minnesota; IA = Iowa; $\mathrm{MO}=$ Missouri; $\mathrm{AK}=$ Arkansas; and MS = Mississippi.

${ }^{\mathrm{z}}$ Growth rate (G; cm/day) and sclerotia (S) measured over a period of 1 week and 12 weeks, respectively. Sclerotia production scored on scale of 0 to 5 , where $0=$ no sclerotium, $1=1$ to 5 sclerotia, $2=6$ to 10 sclerotia, $3=11$ to 15 sclerotia, $4=16$ to 20 sclerotia, and $5=>21$ sclerotia produced. Values followed by the same letter are not significantly different according to Fisher's least significant difference test at $P=0.05$ within each AG/temperature. 
$R$. solani were recovered from the different locations. Of the 143 isolates tested, $51(35.6 \%)$ belonged to AG-1, $9(6.2 \%)$ to AG-2-2, 40 (28\%) to AG-4, and 15 $(10.6 \%)$ to AG-5. The remaining 28 $(19.6 \%)$ isolates failed to anastomose with any of the testers used (AG-1, 2-2, 4, and 5).

Examination of the distribution of isolates belonging to the different AGs (Table 1) showed that AG-4 and AG-5 were found in all the regions sampled. Isolates of AG-1 were absent in samples from the more northern latitudes while isolates of AG-2-2 were absent in samples from the more southern latitudes. At the middle location $\left(40.1^{\circ} \mathrm{N}\right)$, all four groups were present.

Effects of temperature on growth, sclerotia production, and saprophytic survival. There was a positive relationship between temperature and growth rate (Fig. 1). Analysis of variance revealed significant effects due to AG $(G)$, temperature $(T)$, and $G-T$ interaction on growth $(P=$ 0.0001) (Table 2). Although there were differences in growth rate among various isolates, in general, growth rate increased with increase in temperature up to $25^{\circ} \mathrm{C}$ for most isolates from the various AGs examined. However, none of the isolates belonging to $\mathrm{AG}-1$ grew at $5^{\circ} \mathrm{C}$, while growth rate was lower at 5,10 , and $15^{\circ} \mathrm{C}$ compared with 20,25 , and $30^{\circ} \mathrm{C}$ across all AGs (Table 3). Regression analysis of mean growth rate among AGs showed a strong linear relationship (based on $R^{2}$ values) between growth rate and temperature (Fig. 1).

Similar to growth rate, there was variability among isolates in their capacity to produce sclerotia. Analysis of variance showed significant effects for group $(G)$, temperature ( $T)$, and $G-T$ interactions on sclerotia production $(P=0.0001)$ (Table $2)$. Sclerotia production increased with increase in temperature up to $25^{\circ} \mathrm{C}$ with most of the isolates irrespective of $\mathrm{AG}$, after which there was a decline in sclerotia production. However, two isolates, one each belonging to AG-2-2 and AG-4, did not produce any sclerotia across the temperature range tested. Additionally, none of the isolates of the various AGs produced sclerotia at $5^{\circ} \mathrm{C}$ (Table 3). Quadratic regression analysis (Fig. 1) better explained the relationship between sclerotia produc- tion and temperature in AG-1 $\left(R^{2}=0.93\right)$, AG-2-2 $\left(R^{2}=0.86\right)$, AG-4 $\left(R^{2}=0.86\right)$, and AG-5 $\left(R^{2}=0.83\right)$.

The mean initial population densities per gram of straw were $950,550,450$, and 330 CFU for AG-1, AG-2-2, AG-4, and AG-5, respectively. Saprophytic survival ability of all the AGs decreased linearly with decrease in temperature and with increase in time in the survival study (Figs. 2-4 represent temperatures of $-10,10$, and $30^{\circ} \mathrm{C}$, respectively). Figures of temperatures 0 and $20^{\circ} \mathrm{C}$ are not shown, but data on $R^{2}$ values, slopes, and significance of slopes among isolates within each AG are presented (Table 4). Analysis of variance showed significant effects due to group $(G)$, temperature $(T)$, time interval $(T I)$, and for interactions $T-T I$ and $G-T I$ on saprophytic survival ability $(P=0.0001$ Table 2). Saprophytic survival ability of all the isolates from the different AGs declined sharply at $-10^{\circ} \mathrm{C}$ compared with the other temperatures. Although isolates/AG exhibited differential saprophytic survival ability, in general, saprophytic survival ability was better at 10,20 , and $30^{\circ} \mathrm{C}$ compared with -10 and $0^{\circ} \mathrm{C}$, which is indicated

$$
\begin{aligned}
& \text { MO 7-3 } \ln (\mathrm{y})=\ln (9.14)-0.69(\mathrm{x}) \mathrm{R}^{2}=0.92 \\
& \text { MS 3-1 } \ln (\mathrm{y})=\ln (7.84)-0.75(\mathrm{x}) \mathrm{R}^{2}=0.90
\end{aligned}
$$

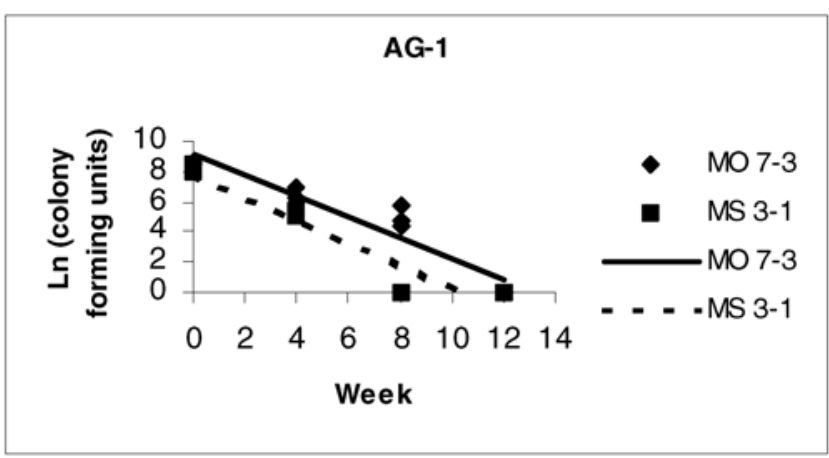

$$
\begin{array}{|l|}
\hline M N ~ 3-1 \ln (y)=\ln (7.18)-0.45(x) R^{2}=0.66 \\
M S 2-8 \ln (\mathrm{v})=\ln (7.73)-0.73(\mathrm{x}) \mathrm{R}^{2}=0.89 \\
\hline
\end{array}
$$

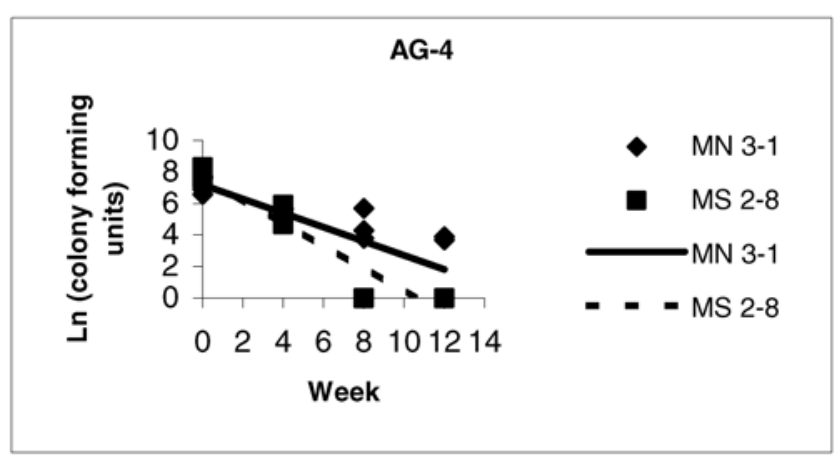

$$
\begin{aligned}
& \text { MN 3-3 } \ln (\mathrm{y})=\ln (7.59)-0.53(\mathrm{x}) \mathrm{R}^{2}=0.69 \\
& M O \quad 7-2 \ln (\mathrm{y})=\ln (8.38)-0.49(\mathrm{x}) \mathrm{R}^{2}=0.75
\end{aligned}
$$

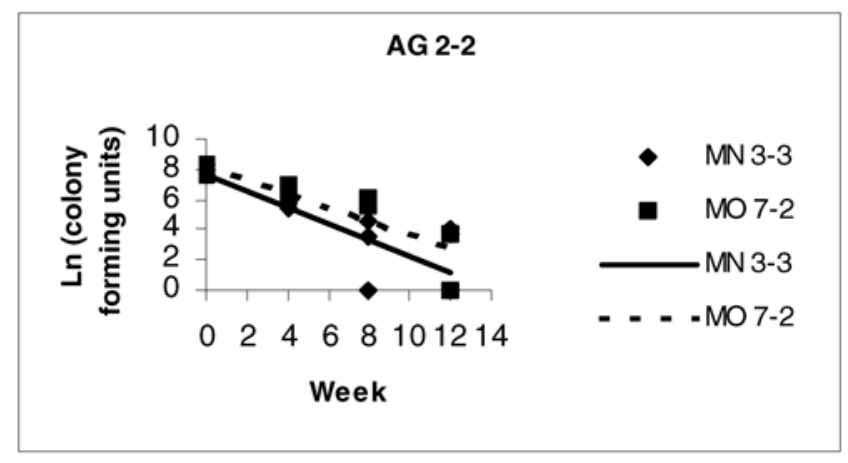

\section{Temperature $\left(-10^{\circ} \mathrm{C}\right)$}

Fig. 2. Regression analysis of the effects of temperature $\left(-10^{\circ} \mathrm{C}\right)$ on the saprophytic survival of two representative isolates of Rhizoctonia solani from anastomosis group (AG)-1 (MO 7-3 and MS-3-1), AG 2-2 (MN 3-3 and MO 7-2), AG-4 (MN 3-1 and MS 2-8), and AG-5 (MN 3-2 and MS 1-10) over a 12week period under in vitro conditions. Each datum point is a mean of two replications and two experiments. 
MO 7-3 $\ln (\mathrm{y})=\ln (8.40)-0.29(\mathrm{x}) \mathrm{R}^{2}=0.96$

MS 3-1 $\ln (y)=\ln (8.03)-0.28(x) R^{2}=0.95$

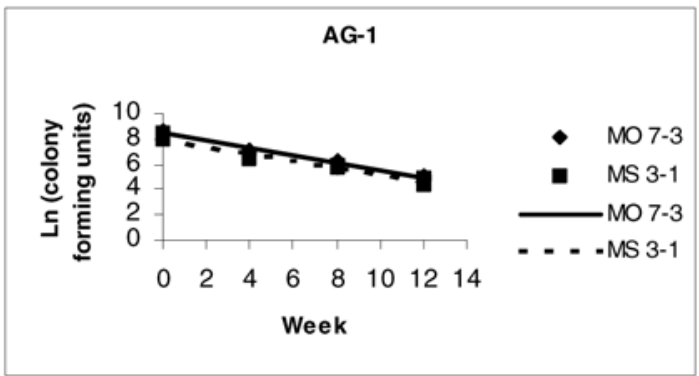

MN 3-1 $\ln (\mathrm{y})=\ln (7.29)-0.19(\mathrm{x}) \mathrm{R}^{2}=0.90$

MS $2-8 \ln (y)=\ln (7.72)-0.23(x) R^{2}=0.91$

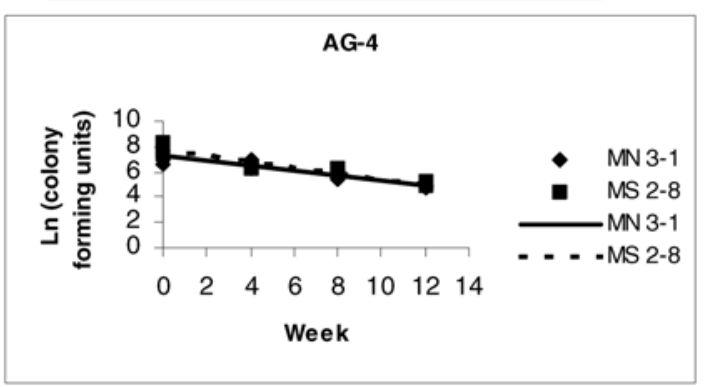

MN 3-3 $\ln (\mathrm{y})=\ln (7.53)-0.22(\mathrm{x}) \mathrm{R}^{2}=0.88$

MO 7-2 $\ln (y)=\ln (7.83)-0.22(x) R^{2}=0.97$

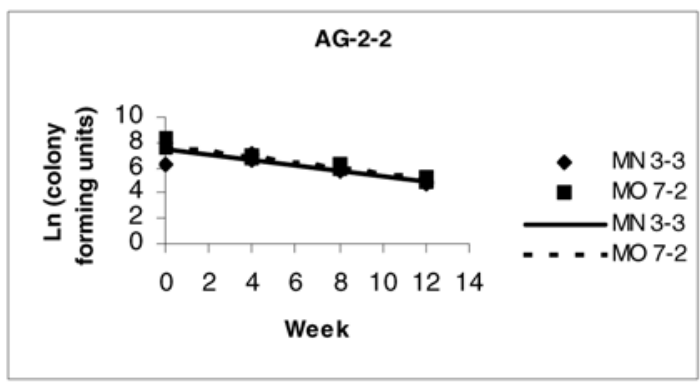

MN 3-2 $\ln (\mathrm{y})=\ln (7.10)-0.20(\mathrm{x}) \mathrm{R}^{2}=0.90$

MS $1-10 \ln (y)=\ln (7.23)-0.23(x) R^{2}=0.89$

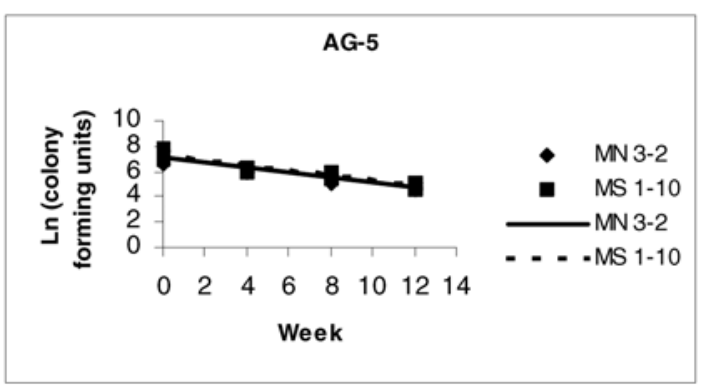

Temperature $\left(10^{\circ} \mathrm{C}\right)$

Fig. 3. Regression analysis of the effects of temperature $\left(10^{\circ} \mathrm{C}\right)$ on the saprophytic survival of two representative isolates of Rhizoctonia solani from anastomosis group (AG)-1 (MO 7-3 and MS-3-1), AG 2-2 (MN 3-3 and MO 7-2), AG-4 (MN 3-1 and MS 2-8), and AG-5 (MN 3-2 and MS 1-10) over a 12week period under in vitro conditions. Each datum point is a mean of two replications and two experiments.
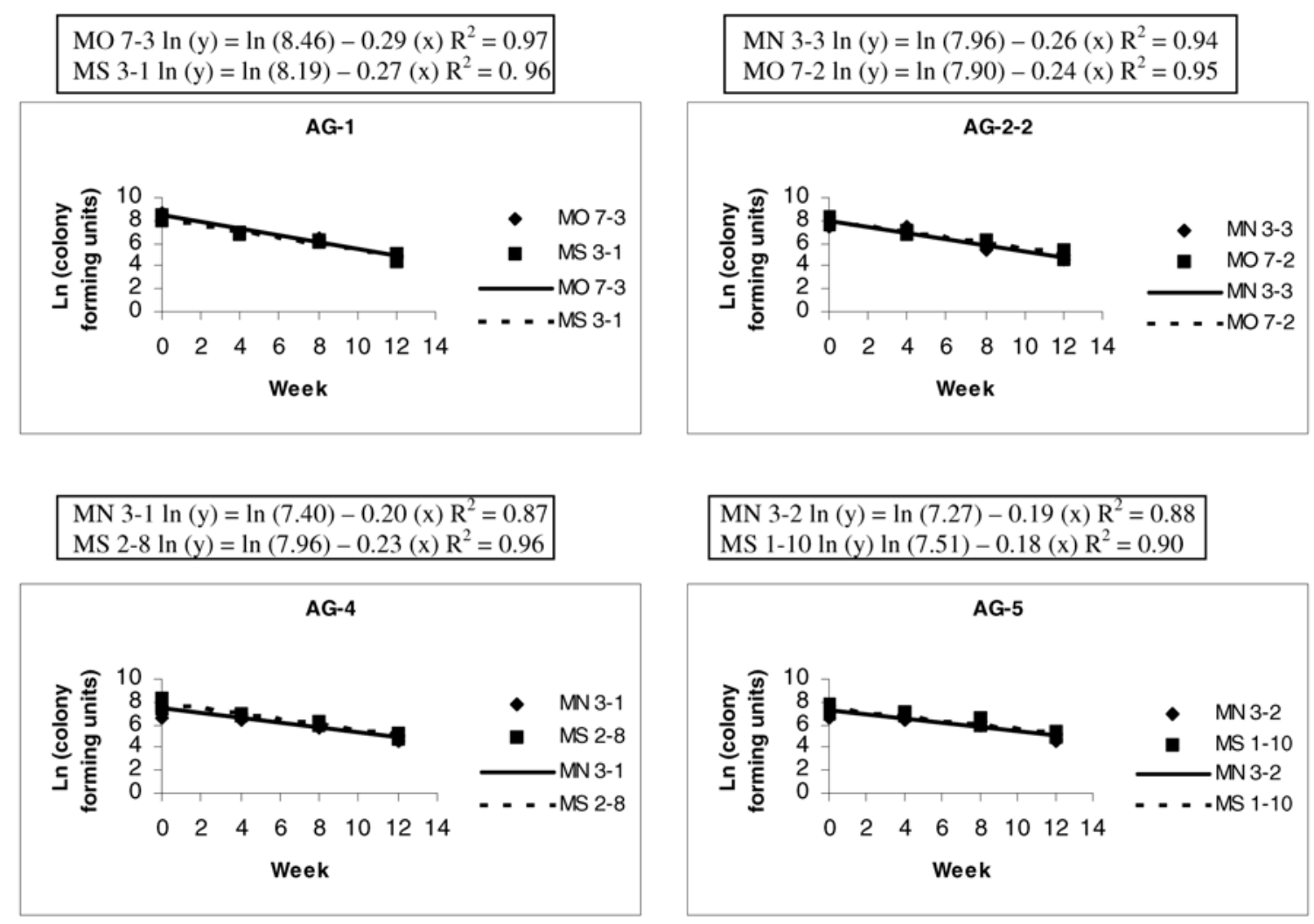

Temperature $\left(30^{\circ} \mathrm{C}\right)$

Fig. 4. Regression analysis of the effects of temperature $\left(30^{\circ} \mathrm{C}\right)$ on the saprophytic survival of two representative isolates of Rhizoctonia solani from anastomosis group (AG)-1 (MO 7-3 and MS-3-1), AG 2-2 (MN 3-3 and MO 7-2), AG-4 (MN 3-1 and MS 2-8), and AG-5 (MN 3-2 and MS 1-10) over a 12week period under in vitro conditions. Each datum point is a mean of two replications and two experiments. 
by shallower slopes for saprophytic survival ability as temperatures increased (Table 4). None of the isolates tested across the temperature range produced any sclerotia during the course of study.

\section{DISCUSSION}

Recovery of different AGs in $R$. solani was affected by latitude (temperature) in this study. AG-1 was found predominantly in the samples from the more southern latitudes while AG-2-2 was mostly found in samples from the more northern and central latitudes. However, AG-4 and AG-5 did not show preference to latitudinal changes in their recovery. Earlier studies have reported differences in recovery of $R$. solani AGs from soybean fields $(6,9)$.

The difference in recovery of AGs along a latitudinal (temperature) gradient could be ascribed to two aspects: (i) a direct effect of temperature on $R$. solani and (ii) indirect effects mediated by the host plants. These results from our study are in agreement with Pirozynski's (11) hypothesis that temperature might be the most important climatic variable affecting fungal distribution. The difference in recovery between AG-1 and AG-2-2 in relation to latitude (temperature) may suggest that these groups are relatively more important in the warmer south and cooler north, respectively. To our knowledge, AG-1 has not been reported in soybean from the northern regions. Additionally, cropping pattern also has been shown to affect the distribution of certain AGs within a particular region (10). Rice is a major crop in the southern states on which AG-1 (AG-1$1 \mathrm{~A}$ and $1-1 \mathrm{~B})$ causes severe sheath and web blights (6). Sheath and web blights caused by AG-1 (AG-1-1A and 1-1B) are more severe when rice is rotated with soybean in particular rather than with other

Table 4. Coefficients of determination $\left(R^{2}\right)$, intercepts, slopes, and significance among slopes, anastomosis group (AG), and temperature for regression of population densities (ln (x)) of Rhizoctonia solani against days after incubation at five different temperatures for four AGs

\begin{tabular}{|c|c|c|c|c|c|}
\hline Temperature $\left({ }^{\circ} \mathbf{C}\right)$, group (isolate) & Latitude $^{\mathrm{z}}$ & $R^{2}$ & Intercept & Slope & $P>F$ \\
\hline \multicolumn{6}{|l|}{-10} \\
\hline AG-1 (MO 7-3) & 40.1 & 0.92 & 9.14 & -0.69 & \\
\hline AG-1 (MS 3-1) & 33.4 & 0.90 & 7.84 & -0.75 & 0.001 \\
\hline AG-2-2 (MN 3-3) & 46.5 & 0.69 & 7.59 & -0.53 & \\
\hline AG-2-2 (MO 7-2) & 40.1 & 0.75 & 8.38 & -0.49 & 0.052 \\
\hline AG-4 (MN 3-1) & 46.5 & 0.66 & 7.18 & -0.45 & \\
\hline AG-4 (MS 2-8) & 33.4 & 0.89 & 7.73 & -0.73 & 0.008 \\
\hline AG-5 (MN 3-2) & 46.5 & 0.64 & 7.39 & -0.50 & \\
\hline AG-5 (MS 1-10) & 33.4 & 0.88 & 7.37 & -0.70 & 0.007 \\
\hline \multicolumn{6}{|l|}{0} \\
\hline AG-1 (MO 7-3) & 40.1 & 0.96 & 8.58 & -0.27 & \\
\hline AG-1 (MS 3-1) & 33.4 & 0.92 & 7.81 & -0.25 & 0.586 \\
\hline AG-2-2 (MN 3-3) & 46.5 & 0.93 & 7.78 & -0.25 & \\
\hline AG-2-2 (MO 7-2) & 40.1 & 0.92 & 7.92 & -0.24 & 0.385 \\
\hline AG-4 (MN 3-1) & 46.5 & 0.87 & 7.33 & -0.25 & \\
\hline AG-4 (MS 2-8) & 33.4 & 0.92 & 7.80 & -0.26 & 0.436 \\
\hline AG-5 (MN 3-2) & 46.5 & 0.92 & 7.30 & -0.27 & \\
\hline AG-5 (MS 1-10) & 33.4 & 0.95 & 7.36 & -0.26 & 0.373 \\
\hline \multicolumn{6}{|l|}{10} \\
\hline AG-1 (MO 7-3) & 40.1 & 0.96 & 8.40 & -0.29 & $\ldots$ \\
\hline AG-1 (MS 3-1) & 33.4 & 0.95 & 8.03 & -0.28 & 0.811 \\
\hline AG-2-2 (MN 3-3) & 46.5 & 0.88 & 7.53 & -0.22 & \\
\hline AG-2-2 (MO 7-2) & 40.1 & 0.97 & 7.83 & -0.22 & 0.785 \\
\hline AG-4 (MN 3-1) & 46.5 & 0.90 & 7.29 & -0.19 & \\
\hline AG-4 (MS 2-8) & 33.4 & 0.91 & 7.72 & -0.23 & 0.412 \\
\hline AG-5 (MN 3-2) & 46.5 & 0.90 & 7.10 & -0.20 & \\
\hline AG-5 (MS 1-10) & 33.4 & 0.89 & 7.23 & -0.23 & 0.708 \\
\hline \multicolumn{6}{|l|}{20} \\
\hline AG-1 (MO 7-3) & 40.1 & 0.93 & 8.33 & -0.24 & \\
\hline AG-1 (MS 3-1) & 33.4 & 0.95 & 8.10 & -0.24 & 0.785 \\
\hline AG-2-2 (MN 3-3) & 46.5 & 0.92 & 7.80 & -0.25 & \\
\hline AG-2-2 (MO 7-2) & 40.1 & 0.93 & 7.80 & -0.23 & 0.708 \\
\hline AG-4 (MN 3-1) & 46.5 & 0.88 & 7.34 & -0.23 & \\
\hline AG-4 (MS 2-8) & 33.4 & 0.96 & 7.92 & -0.24 & 0.412 \\
\hline AG-5 (MN 3-2) & 46.5 & 0.87 & 7.31 & -0.23 & \\
\hline AG-5 (MS 1-10) & 33.4 & 0.88 & 7.35 & -0.22 & 0.329 \\
\hline \multicolumn{6}{|l|}{30} \\
\hline AG-1 (MO 7-3) & 40.1 & 0.97 & 8.46 & -0.29 & \\
\hline AG-1 (MS 3-1) & 33.4 & 0.96 & 8.19 & -0.27 & 0.335 \\
\hline AG-2-2 (MN 3-3) & 46.5 & 0.94 & 7.96 & -0.26 & 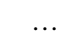 \\
\hline AG-2-2 (MO 7-2) & 40.1 & 0.95 & 7.90 & -0.24 & 0.115 \\
\hline AG-4 (MN 3-1) & 46.5 & 0.87 & 7.40 & -0.20 & \\
\hline AG-4 (MS 2-8) & 33.4 & 0.96 & 7.96 & -0.23 & 0.136 \\
\hline AG-5 (MN 3-2) & 46.5 & 0.88 & 7.27 & -0.19 & \\
\hline AG-5 (MS 1-10) & 33.4 & 0.90 & 7.51 & -0.18 & 0.987 \\
\hline
\end{tabular}

${ }^{\mathrm{z}}$ Origin of isolate.

crops (2). However. in the north, soybean commonly is rotated with corn on which AG-2-2 has been reported to cause crown and brace root rot (15). The recovery of AG-4 and AG-5 from all locations sampled further indicates that some AGs may be more adapted to temperature variation, cropping patterns, and wider host range than others. Another factor not considered in this study but which could potentially affect the distribution of different AGs of $R$. solani, and particularly AG-1, is rainfall. Relatively, southern regions receive more rainfall compared with northern regions.

Growth of the representative isolates of the different AGs increased with increase in temperature up to $25^{\circ} \mathrm{C}$, after which the growth rate leveled off. The growth response noticed in this study is similar to what has been reported in the literature (14). Sclerotia production increased up to $25^{\circ} \mathrm{C}$, but at $30^{\circ} \mathrm{C}$ all the isolates tested from the different AGs showed a decline (Fig. 1; Table 3). Generally, all the representative isolates from the different AGs produced fewer or no sclerotia at the lower ends of the temperatures tested. The optimum temperature range reported for sclerotia production in $R$. solani is between 18 and $21^{\circ} \mathrm{C}(17)$. However, isolates tested in this study showed a higher optimum $\left(25^{\circ} \mathrm{C}\right)$ for sclerotia production. In the survival study, variability was noticed among the isolates within different AGs. All the isolates irrespective of AG survived less efficiently at lower temperatures. Although only two isolates were tested within each AG, isolates of AG-1 and isolates from southern locations $\left(<40.1^{\circ} \mathrm{N}\right)$ irrespective of the AG had a tendency for faster decline in saprophytic survival compared with isolates from the northern locations at lower temperature $\left(-10^{\circ} \mathrm{C}\right.$; Fig. 2 ; Table 4). The faster decline in population density of the more southern isolates (irrespective of AG) at lower temperature could be due their inability to withstand cooler conditions because the mean minimum temperatures during the winter months are much cooler in the more northern latitudes. However, this survival study was conducted using autoclaved soil; therefore, in nature, there could be a potentially added influence of the native microflora on the survival of different AGs of $R$. solani.

Results from this study indicate differential recovery pattern among AGs of $R$. solani from soybean fields over a large geographic range. The differentiation of AGs based on latitude, especially for AG-1 and AG-2-2, may be due to more favorable environment, host range, or both. Therefore, it is plausible that temperature might play an important role in the distribution of some AGs in soybean on the macro scale (large geographic level) whereas, on a micro scale (regional level), the variation in the distribution of AGs in soybean might be influenced by the different farming practices adopted at the regional level. 
Although this study was limited in the number of sampling sites, more research on how cropping practices affect the occurrence of different AGs in relation to temperature may provide a better knowledge about the distribution of different AGs of $R$. solani in soybean. In summary, growth rate and sclerotia production were similar among the four AGs tested. However, there were differences in saprophytic survival at different temperatures among isolates from the different AGs. Additionally, isolates of AG-1 survived poorly at the lower end of temperature range tested. Further, the results revealed clear differences between northern and southern isolates irrespective of AG in their capacity to survive saprophytically at $-10^{\circ} \mathrm{C}$. A better understanding of the distribution of different AGs in $R$. solani in relation to temperature will increase our knowledge about different AGs in $R$. solani and, thus, will help in devising disease management tactics.

\section{ACKNOWLEDGMENTS}

We thank B. Zhang for his help during the soil sample collection and P. Lundeen for his assistance.

\section{LITERATURE CITED}

1. Bandoni, R. J. 1979. Safranin O as a rapid stain for fungi. Mycologia 71:873-874.

2. Belmar, S. B., Jones, R. K., and Starr, J. L.
1987. Influence of crop rotation on inoculum density of Rhizoctonia solani and sheath blight incidence in rice. Phytopathology 77:11381143.

3. Carling, D. E. 1996. Grouping in Rhizoctonia solani by hyphal anastomosis reactions. Pages 37-47 in: Rhizoctonia species: Taxonomy, Molecular Biology, Ecology, Pathology, and Disease Control. B. Sneh., Jabi-Hare, S., Neate, S., and Dijist, eds. G. Kluwer Academic Publishers, Dordrecht, The Netherlands.

4. Carling, D. E., Baird, R. E., Gitaitis, R. D., Brainard, K. A., and Kuninaga, S. 2002. Characterization of AG-13, a newly reported anastomosis group of Rhizoctonia solani Phytopathology 92:893-899.

5. Harikrishnan, R., and Yang, X. B. 2000. Latitudinal distribution of different anastomosis groups of Rhizoctonia solani in soybean fields (Abstr.). Phytopathology 90:S34.

6. Jones, R. K., and Belmar, S. B. 1989. Characterization and pathogenicity of Rhizoctonia spp. isolated from rice, soybean, and other crops grown in rotation with rice in Texas. Plant Dis. 73:1004-1010.

7. Kronland, W. C., and Stanghellini, M. E. 1988. Clean slide technique for the observation of anastomosis and nuclear condition of Rhizoctonia solani. Phytopathology 78:820-822.

8. Muyolo, N. G., Lipps, P. E., and Schmitthenner, A. F. 1993. Anastomosis grouping and variation in virulence among isolates of Rhizoctonia solani associated with dry bean and soybean in Ohio and Zaire. Phytopathology 83:438-444.

9. Nelson, B., Helms, T., Christianson, T., and Kural, I. 1996. Characterization and patho- genicity of Rhizoctonia from soybeans. Plant Dis. 80:74-80.

10. Parameter, J. R., Jr., Sherwood, R. T., and Platt, W. D. 1969. Anastomosis grouping among isolates of Thanatephorus cucumeris. Phytopathology 59:1270-1278.

11. Pirozynski, K. A. 1968. Geographical distribution of fungi. Pages 487-504 in: The Fungi, Vol III. G. C. Ainsworth and A. S. Sussman, eds. Academic Press, New York..

12. Rush, C. M., Carling, D. E., Harveson, R. M. and Mathieson, J. T. 1994. Prevalence and pathogenicity of anastomosis groups of Rhizoctonia solani from wheat and sugar beet in Texas. Plant Dis. 78:349-352.

13. Sinclair, J. B., and Backman, P. A., eds. 1989 Compendium of Soybean Diseases. 3rd ed. American Phytopathological Society, St. Paul, MN.

14. Sneh, B., Burpee, L., and Ogoshi, A. 1991 Identification of Rhizoctonia species. American Phytopathological Society, St. Paul, MN.

15. Sumner, D. R., and Bell, D. K. 1982. Root diseases induced in corn by Rhizoctonia solani and Rhizoctonia zeae. Phytopathology 72:8691.

16. Tachibana, H., Jowett, D., and Fehr, W. R. 1971. Determination of losses in soybean caused by Rhizoctonia solani. Phytopathology 61:1444-1446.

17. Tyner, L. E., and Sanford, G. B. 1935. On the production of sclerotia by Rhizoctonia solani Kuhn in pure culture. Sci. Agric. 16:197-207.

18. Windels, C. E., and Nabben, D. J. 1989. Characterization and pathogenicity of anastomosis groups of Rhizoctonia solani isolated from Beta vulgaris. Phytopathology 79:83-88. 